\title{
Introduction: reconsidering cultural heritage in East Asia
}

\author{
Akira Matsuda $^{*}$ and Luisa Elena Mengoni ${ }^{\dagger}$ \\ ${ }^{\star}$ University of Tokyo \\ ${ }^{\dagger}$ Victoria and Albert Museum
}

The seven chapters of this book examine a range of issues related to cultural heritage in East Asia, including perspectives from the fields of anthropology, ethnology, sociology and art history. While these contributions reflect the different disciplinary backgrounds of the authors, there is one element that pertains to all of them: they do not regard cultural heritage as a given but rather as something that is made and being constantly remade. The book as a whole can therefore be understood to consider how cultural heritage is conceptualised, materialised, experienced and negotiated

\section{How to cite this book chapter:}

Matsuda, A and Mengoni, L E 2016 Introduction: reconsidering cultural heritage in East Asia. In: Matsuda, A and Mengoni, L E (eds.) Reconsidering Cultural Heritage in East Asia, Pp. 1-13. London: Ubiquity Press. DOI: http://dx.doi.org/10.5334/baz.a. License: CC-BY 4.0 
in various cultural, political and social contexts in East Asia. This approach - to view cultural heritage as a construct or a process is not new and has already been at the heart of 'heritage studies' for over a decade (Byrne 2008; Harvey 2001; Smith 2006). What characterises this book, however, is that it applies the approach to cultural heritage in East Asia, an area which has tended not to be extensively explored and critically scrutinised. While for the purpose of this book East Asia is represented by Japan, China and Korea, in future it would be desirable to extend the scope of examination to include other neighbouring countries.

\section{Differentiation and assimilation of heritage in East Asia}

As with other geographically defined notions of cultural heritage, such as Western European heritage and African heritage, cultural heritage in East Asia tends to be understood in terms of its local specific manifestations, thus emphasising its difference from heritage in other regions. Its commonly recognised expressions are often related to certain distinctive cultural and social aspects, such as Confucian values, Daoist philosophy, Buddhist religious practices, languages based on ideograms and the use of specific local resources and technologies. This is of course unavoidable to some degree, since cultural heritage is closely associated with peoples' identities, which is in part predicated on the idea of how a group of people is different from others. The underlying logic here is that different groups of people identify with different expressions of heritage. Such a logic often leads to an 'exoticised' notion of cultural heritage, conceptualised through selection for representation vis-à-vis other countries and regions (see Gupta \& Fergusson 1992). The same logic can also result into simplified narratives, 
particularly when one attempts to interpret influences, integrations or hybrid and complex material manifestations of heritage.

Seeing heritage as solely a marker of difference is, however, limiting because it can not only exoticise and/or simplify a culture, but also essentialise it: highly recognisable exotic aspects of cultural heritage tend to be understood as fixed and unchangeable in people's imagination (Sahlins 1993). Both outside observers and local people can be complicit in this process. For example, locals may 'strategically essentialise' their own culture by portraying their heritage as exotic to outsiders in order to gain more recognition (Spivak 1988; Sylvain 2005). In fact, what we regard as 'cultural heritage' often results from a web of interactions and exchanges between various groups and has been changing and reconstructed over time by all the actors involved.

Thinking of cultural heritage as a marker of difference is limiting also because it discourages the understanding of how the heritage of one place can be similar to the heritage of another place. Just as people's group identity is predicated on both how a group is different from others and how the members of the same group share common traits, cultural heritage of a place is conceptualised not only in terms of how it is different from heritage elsewhere but also in terms of what commonalities are shared amongst a variety of heritage expressions existing in that place. In other words, in people's imagination, geographically defined cultural heritage assimilates differences within itself. For example, despite the commonly accepted understanding that there is a variety of cultural heritage expressions across Japan, most people are ready to talk about 'Japanese heritage'; they hardly doubt that the notion of 'Japanese heritage' is impossible. This points to the need of investigating how the imagined notion of 'Japanese heritage' is able to assimilate the diversity of local differences within 
Japan, making people believe that there is a similarity of heritage practices and manifestations across Japan. The same can be said of 'Chinese heritage' and 'Korean heritage', and also of 'East Asian heritage'. When we talk about 'East Asian heritage', we assume, naturally and uncritically, that differences between and across Japanese, Chinese and Korean heritage can somehow be subsumed under the notion of 'East Asian heritage'. This of course can be a problematic and politically dangerous assumption, but is also unavoidable to certain extent because the very nature of cultural heritage is not only to divide but also unite. Seeing cultural heritage only as a marker of difference is limiting in this sense.

Leading on from this idea, we wish to encourage the reader to consider how the dual and dialectical mechanism of differentiation and assimilation of heritage operates in East Asia, both at the level of each country and of the region as a whole. On the one hand, there is a need to understand how the notions of Japanese, Chinese and Korean heritage assimilate differences within each country to propose a unified concept, and likewise, how the notion of East Asian heritage assimilates differences within the region. On the other hand, it is also necessary to examine the tension and dissonance caused by the assimilation of differences, which could lead to the unsettling and re-conceptualisation of existing notions of heritage.

It is also relevant to consider how heritage notions can be transformed and re-negotiated by the actors involved, depending on their agendas and aspirations. A number of chapters in the book address such dialectic shaping and reshaping of cultural heritage. Svensson's chapter (Chapter 3), for example, examines the tension related to the way in which halls where rural lineage-based practices traditionally take place in China have been designated officially and used increasingly for tourism, while also continuing to 
act as places for local ancestral worship. Against the background of rapid economic growth nationwide, the Chinese government is both tightening/regulating and internationalising its management of cultural heritage, as it can serve as a symbol of national pride, global prestige and as a resource for tourism development. The 'authorized heritage discourse' (Smith 2006) that underpins such governmental initiatives is dominant and is gradually transforming rural cultural practices into official heritage, causing conflict with the local discourse that has traditionally been sustaining customs of ancestor worship.

Yang (Chapter 5) also looks into the tension caused by different understandings and uses of cultural heritage in China, analysing the relationship between tourism development and local practices related to ethnic heritage. The rapid expansion of tourism in Yunnan province is increasingly changing customs and lifestyles of the Naxi and Moso ethnic groups, and one can see how their cultural heritage, both tangible and intangible, is gradually staged and used to attract more tourists. Yet, just as globalisation spurs localisation as a reaction (Featherstone 1995: 94-97; Harvey 1989: 302-303), the commodification of ethnic heritage has urged Naxi and Moso communities to take new initiatives to regain control over its management and representation.

Asakura's chapter (Chapter 6), examining cultural heritage in Korea from a Japanese comparative perspective, includes an analysis of the 'making' of Korean and Japanese food. He contends that the Korean government has in recent years been actively involved in the authentication and promotion of Korean food, whereas in Japan similar matters concerning Japanese food have traditionally been and still are dealt with by private initiatives. The 'Japan-Korea Kimchi War' - which Asakura mentions as an example of the Korean government's attempt to strengthen the 
brand of Korean food internationally - is interesting in that it illustrates the nation's claim as the owner of 'national food'. The fact that Kimchi has been appreciated in the international market regardless of the consumers' knowledge of whether it is made in Korea or Japan suggests that it could potentially be considered as 'East Asian food'. And yet, the dissonance within East Asia in this case, between Korea and Japan - makes Kimchi distinctly Korean, and thus does not easily confer on it the status of 'East Asian heritage'.

\section{Temporality of heritage}

Another theme that we wish to highlight in this book is the temporality of heritage, that is to say, the ways in which cultural heritage represents time or is related to conceptions of time. Ogino addresses this theme most directly in his chapter (Chapter 2) by discussing the discourse of cultural heritage management in Japan. He considers two different modes of the temporality of heritage in Japan. Using the term 'the logic of actualisation' he first argues that there has been a tradition in Japan that the past is 'brought up to date' in the present through the medium of cultural heritage. He contrasts this tradition with the linear notion of time upon which the Western concept of heritage and museums largely rest. He contends that the logic of actualisation has been a solution to the difficulty of connecting the pre-modern past of Japan to the future envisioned by modernity, the latter being effectively a concept imported from the West.

Ogino then draws our attention to another mode of the temporality of heritage - the preservation of the present. He argues that people living in late modern societies are increasingly seeing themselves as an object to be perceived from an external world, 
while at the same time they, as a subject, engage with their own world in everyday life. This 'doubling of the world', he argues, accounts for the proliferation of the preservation of the present: we are getting to see the present world as if it were already heritage to be archived and safeguarded.

What deserves particular attention in Ogino's argument is that while his logic of actualisation is discussed in relation to Japan, the preservation of the present is observable not only in Japan but in late modern societies across the globe. This raises an interesting question as to whether the logic of actualisation applies also to China and Korea, which have equally been faced with the challenge of reconciling tradition and modernity since the 19th-century. Lai's investigation (Chapter 4 ) of the social and political circumstances in which the state legislation for the protection of cultural relics was established in the early period of the Republic of China (1912-49) is relevant here, since attempts to construct Chinese heritage - or the transformation of 'cultural property' of imperial and private ownership into public and state-owned 'cultural heritage' - occurred as China began modernising itself. Lai contends that the national system for the protection of cultural relics was established on the one hand due to China's modernisation and the introduction of Western values and disciplines, and on the other hand in the context of the removal of ancient relics from China by Westerners.

Good (Chapter 8) discusses how social memories of devastating earthquakes have been passed down in Japan. Her main focus is on the preservation of materials damaged by the 2011 Great East Japan Earthquake and Tsunami, which is a striking example of the preservation of the present. It is noteworthy that immediately after the catastrophic tsunami there were already calls for preserving damaged ruins in the stricken areas. As Good explains, there were opinions both for and against such calls. Some local 
residents objected to the idea of preserving ruins as monuments because they wanted to move on with their own lives, and with the recovery of their communities, without being constantly reminded of the painful experience of the tsunami. The argument for the preservation of the ruins, on the other hand, stressed the importance of remembering the disaster and passing on the lessons learned from it to future generations, so that the damage caused by similar disasters could be prevented or mitigated in the future. While both opinions are understandable, there is clearly a modernist undertone in the pro-preservation opinion - human society should, and can, reduce the risk of natural disaster. The idea expressed by some of the pro-preservation group members to link the preserved 'disaster heritage' to tourism development is also uncompromisingly modernist: heritage is regarded here as a resource to capitalise on. One can thus argue that attempts to preserve ruins resulting from the 2011 Great East Japan Earthquake and Tsunami as 'disaster heritage' were an extreme manifestation of modernity: ordinary materials that were part of people's everyday world yesterday can become ruins that have social and educational value today, going on to be preserved, commemorated and used as heritage tomorrow.

\section{Terminology of heritage}

A final theme that we wish to address in this book is the body of terms involved in and used to discuss the 'making' of cultural heritage in East Asia. Language is at the core of constructing meaning, and the making of heritage depends on, and is conditioned by, terminology. In Britain, for example, the term 'heritage' came into full use in official language from about 1975 (Larkham 1999: 115-116) and in people's everyday language from about the early 
1980s - this broadly coincided with the emergence of the "heritage discourse', prompted by the adoption of UNESCO's World Heritage Convention in 1972 and the establishment of English Heritage in 1983. Previously, people used more specific terms 'monuments', 'historic buildings', 'archaeological sites', 'works of art' or 'relics' for example - referring to components of what we mean today by 'cultural heritage.' One can thus infer that people identified with the past through a variety of means, which, however, remained conceptually discrete since there was no overall notion of 'cultural heritage' that could integrate them.

The heritage discourse beginning from about the 1980s has subsequently gradually developed, not only in Britain but globally, and this has come to require new, more complex terminology. While the initial range of terms used to describe the categories of cultural heritage was more or less limited to 'architectural heritage' and 'archaeological heritage', or 'national heritage, 'local heritage' and 'World Heritage', it has since diversified greatly. Today in heritage studies there are discussions of 'intangible heritage' (Smith \& Nakagawa 2009; see also Ogino's Chapter 2, Svensson's Chapter 3, Fuquan's Chapter 5 and Asakura's Chapter 6), 'industrial heritage' (Douet 2012; Oevermann \& Mieg 2014), 'urban heritage' (Lorgan 2002), 'ethnic heritage' (Hendersson 2003), 'living heritage' (Stovel et al. 2005), 'maritime heritage' (Laurier 1998), 'difficult heritage' (Macdonald 2009) and so on. All of these categories can, of course, apply to cultural heritage in East Asia, and it would also be possible to add more categories to refine the conceptualisation of heritage further. In this book, for example, Good (Chapter 8) discusses the term/concept of 'disaster heritage'.

Two chapters in the book address the making of terminology related to cultural heritage in East Asia more directly. Mouri 
(Chapter 7) examines the extent to which the term/concept of 'cultural landscape' has been accepted in Japan through a case study of Tomo, a port town with a historic landscape that was recently threatened by the proposal to construct a bridge. He first compares UNESCO's definition of 'Cultural Landscape' with three similar and yet slightly different categories of cultural properties in Japan - and one must note here that in Japan 'cultural properties' is the term legally and administratively employed to refer to cultural heritage (Matsuda 2014: 4156). It is notable that the Japanese term 'bunkateki keikan' is a direct translation of the English 'cultural landscape', and yet it still differs from UNESCO's 'Cultural Landscape'. Mouri argues that this difference can be explained by the pre-existence of other related categories of cultural properties in Japan: in particular, meishô and dentôteki kenzôbutsugun hozon chiku. Meishô, a traditional term/concept that has existed in Japan much longer than 'cultural landscape', is essentially a 'culturally appreciated place', and as such is different from 'cultural landscape' which is defined in terms of the history of human interactions with a place as can be read from its visual appearance. In other words, the visual appearance matters more in a 'cultural landscape' than in a meishô. This demonstrates that both 'cultural landscape' and meishô are culture-specific concepts, at least in their origin.

Lai (Chapter 4) scrutinises the legal and historical documents related to the process of establishing the national system for protecting cultural heritage in early 20 th-century China. This process began by legally defining what cultural heritage is, and one can note here the first uses of a particular terminology. Lai explains that the terms/concepts such as guwu (ancient relics), shiji (historic sites), guji (ancient sites), mingsheng (famous sights), wenwu (cultural relics) and guobao (national treasure) all came into use 
during this period, which marked 'the birth of modern China' these new terms being necessary in order to legally transform imperial collections into state properties.

Finally, from a cross-regional perspective it is worth noting that the Japanese, Chinese and Korean translations for the English 'cultural heritage' - 'wenhua yichan', 'bunka isan' and 'munhwayusan', respectively - became popular only from about the 1980s and the early 1990s (see Lai Chapter 4 for 'wenhua yichan', and Matsuda 2013: 23-24 for 'bunka isan'). This is probably the result of the widespread adoption of the so-called 'internationally recognised standards' developed and advocated by UNESCO and other international organisations across the World; China, for example, ratified the UNESCO's World Heritage Convention in 1985, and Japan accepted it in 1992 and the Republic of Korea in 1988. Such a recent and rapid acquisition of the heritage concept can be connected to the need of East Asian countries to align themselves to the international scene and engage more actively with their own cultural heritage as a strategy to manage the portrayal and use of their respective pasts in a coherent and programmatic fashion.

However, as a number of the chapters in this book suggest, cultural heritage is fundamentally fluid and never subject to total control by any institution. It would therefore be unproductive to consider what exactly constitutes 'Japanese heritage', 'Chinese heritage', 'Korean heritage' or 'East Asian heritage' - such questioning is promised not to yield a complete, satisfactory answer. Far more constructive will be, instead, to examine how and why different actors in East Asia employ and deploy the notion of heritage on each relevant occasion, with multiple dynamics and strategies at play - this is exactly what we wish to propose in this book. Ultimately, reconsidering cultural heritage in East Asia is 
necessary not so much because we need to understand what East Asian heritage precisely is, but because we need to understand how people 'go about' cultural heritage in East Asia.

\section{References}

Byrne, D 2008 Heritage as Social Action. In: Fairclough, G, Harrison, R, Jameson, J H Jr and Schofield, J (eds.) The Heritage Reader. Abingdon and New York: Routledge. pp. 149-173.

Douet, J (ed.) 2012 Industrial Heritage Re-tooled: The TICCIH guide to Industrial Heritage Conservation. Lancaster: Carnegie. Featherstone, M 1995 Undoing Culture. London, Thousand Oaks and New Delhi: Sage.

Gupta, A and Ferguson, J 1997 Beyond "Culture": Space, Identity, and the Politics of Difference. Cultural Anthropology, 7: 6-23.

Harvey, D 1989 The Condition of Postmodernity: An Enquiry into the Origins of Cultural Change. Oxford: Blackwell.

Harvey, D C 2001 Heritage Pasts and Heritage Presents: Temporality, Meaning and the Scope of Heritage Studies. International Journal of Heritage Studies, 7 (4): 319-338.

Henderson, J 2003 Ethnic Heritage as a Tourist Attraction: The Peranakans of Singapore. International Journal of Heritage Studies, 9 (1): 27-44.

Larkham, P 1999 Preservation, Conservation and Heritage: Developing Concepts and Applications. In: Cullingworth, B (ed.) British Planning: 50 Years of Urban and Regional Policy. London: Athlone Press. pp. 105-122.

Laurier, E 1998 Replication and Restoration: Ways of Making Maritime Heritage. Journal of Material Culture, 3 (1): 21-50.

Logan, W S 2002 The Disappearing 'Asian' City: Protecting Asia's

Urban Heritage in a Globalizing World. Hong Kong: Oxford University Press.

Macdonald, S 2009 Difficult Heritage: Negotiating the Nazi Past in Nuremberg and Beyond. London and New York: Routledge. Matsuda, A 2013 Paburikku Akeorojî No Kanten Kara Mita Kôkogaku, Bunkazai, Bunkaisan (Archaeology, Buried 
Cultural Properties and Cultural Heritage as Seen from the Viewpoint of Public Archaeology). Quarterly of Archaeological Studies (Kôkogaku Kenkyû), 60 (2): 19-33.

Matsuda, A 2014 Japan: Cultural Heritage Management. In: Smith, C (ed.) Encyclopaedia of Global Archaeology. New York: Springer. pp. 4156-4160.

Oevermann, H and Mieg, H A (eds.) 2014 Industrial Heritage Sites in Transformation: Clash of Discourses. New York: Routledge. Sahlins, M 1993 Goodby to Tristes Tropes: Ethnography in the Context of Modern World. History. Journal of Modern History, 65 (1): $1-25$.

Smith, L 2006 The Uses of Heritage. London: Routledge.

Smith, L and Akagawa, N (eds.) 2009 Intangible Heritage. London: Routledge.

Spivak, G 1988 Subaltern Studies: Deconstructing Historiography. In: Guha, R. and Spivak, G. (eds.) Other Worlds: Essays in Cultural Politics. Oxford: Oxford University Press. pp. 197-221. Stovel, H, Stanley-Price, N and Killick, R (eds.) 2005 Conservation of Living Religious Heritage. Rome: ICCROM.

Sylvain, R 2005 Disorderly Development: Globalization and the Idea of "Culture" in the Kalahari. American Ethnologist, 32 (3): 354-370. 